\title{
ASSESSING IMPACT OF SMART BRAKE BLENDING TO IMPROVE ACTIVE SAFETY CONTROL BY USING SIMULINK
}

UDC:629.3.017.5:004.8

Original scientific paper

https://doi.org/10.18485/aeletters.2021.6.1.4

\author{
Lalit N. Patil*1, H. P. Khairnar ${ }^{1}$ \\ ${ }^{1}$ Department of Mechanical Engineering, Veermata Jijabai Technological Institute (VJTI), Mumbai, India
}

\begin{abstract}
:
Not just emissions issues, but also rising fuel costs for traditional cars is attracting individuals to make use of electric vehicles. Despite various benefits, such as pollution-free, noise-free, smooth driving, there may be a new likelihood of problems resulting from the quiet service of electric cars (EVs) which difficult to hear for pedestrians as well as wear particles coming out from disc brake are still unresolved issue from atmospheric state. In view of this, Authors have designed an intelligent braking system to address such issues. The aim of the proposed work is to construct an intelligent model of braking system that can incorporate contactless blending braking along with safety controls to prevent any collision. A state flow algorithm along with obstacle detection has been introduced to achieve desired braking action from proposed model. The results obtained from simulation study are consistent relative to previous researchers' findings. The new scheme has to be aiming to mitigate concerns over injuries and enhancing environmental conditions. The main contribution of the present study is the novel design of braking system test rig with the application of artificial intelligence to improve active safety control of vehicles.
\end{abstract}

\section{ARTICLE HISTORY}

Received: 17.01.2021.

Accepted: 22.03.2021

Available: 31.03.2021.

\section{KEYWORDS}

Electric vehicles, Contactless Brakes, State Flow Strategy, Road Safety

\section{INTRODUCTION}

Rapid technical advancements in the automotive industry worldwide are intended to make reliable, better and safer cars [1]. Automobile braking has a significant effect on automotive stability and safety. Although the brake system is a crucial component of successful automotive safety controls, the keen attentions required by the drivers is also considered as a significant factor. Driver distraction is caused by a number of causes, including Advanced Driver Assistance Systems (ADAS), advertisements shown on the lane, and the use of car devices, among others [2-4]. Basically, the distractions are categorized into three groups such as visual distraction, manual distraction and cognitive distraction. The detachment of your eyes from the road indicates visual distraction where influences include smart phone handling, temperature change, and mirror-looking appearance. Manual distractions include taking hands from the steering wheel in cases such as eating or drinking while driving, changing seat belts, and running driver assistance systems/music systems. The type of cognitive distraction involves drowsiness, communicating to people in cars, talking on the telephone while driving.

The success of electric vehicles is attributed not only to the government regulations on the use of electric vehicles, but also to the growing trend pursued by fuel prices $[5,6]$. The benefits of electric cars are the noiseless design, safer for the atmosphere, and the low operating costs [7]. However, the low noise of electric vehicles could pose the new unintentional risk to pedestrians in regards to safety [8]. Furthermore, the pollution effects due to frequent use of disc brake is discussed less in previous researches [9]. Therefore, this article is intended to introduce a 
novel kind of smart braking system which will address the safety and pollution concerns to enhance the global road safety not only for road users but also for drivers along with passengers.

Notwithstanding comfort travel, road traffic accidents (RTA) are the most important issue, especially in urban areas. The growing urbanisation trend is driving people to migrate to urban areas for different business and activities, especially in the developed countries such as India, which may be a significant cause of high traffic in metro towns [10]. Around the same time, there could be a chance of accidental incidence when there are millions of pedestrians passing on the road every day. Thereby, it becomes foremost need of development of the smart system to reduce such kind of incidences. Every proposed system needs to be evaluating cautiously to examine its possible real time events with simulation. Simulink has demonstrated its ability to simulate the proposed model with correctness in outcomes among different simulation methods.

Capturing comprehensive knowledge in realtime contexts and acting on it is very much feasible in this era of technological revolutions. Since microcontrollers/programmable logic controllers can replace huge computerised systems with smart controls, programme executions can be implemented on the device to behave appropriately/control the system [2]. Various sensors, actuators, and appropriate controls bring the concept to life for advanced monitoring of any device as and when needed with automation. As a result, constructing a model and determining the correctness of the proposed model are equally important for improved outcomes. Keeping this view in mind, authors have developed the smart control braking model through simulink to assess feasibility of proposed model.

\section{RELATED WORK}

In numerous studies of road safety, besides the distraction of drivers and pedestrian mistakes, driver's behavior factors are also found significantly responsible for increased accidents/incidents trends across the globe. Considering safety for drivers, various safety addons like air bag, driver's behavior monitoring schemes have been implemented across the world to ensure the safety for drivers as well as passengers. Since then, continuous research has been focused to enhance not only safety concerns but also improvements in atmospheric situations by reducing air pollutions.

Kalikate et al. [11] has developed simulation based model in MATLAB to evaluate performance of Magnetorheological (MR) brakes system. A results obtained from their study indicates that the condition requirement of braking was not evidently fulfilled by a single disc MR brake system. Numerous experimental trials along with magnetorheological brake by means of superimposed magnetic fields were performed to evaluate not only magnetic field superposition but also performance of individual input current as well as preliminary dynamic behavior [12]. Khairnar et al. [13] has employed a simulationbased approach to calculating the coefficient of friction under different longitudinal force conditions, and has discovered that the maximum coefficient of friction value for symmetric shoe length is 0.7 , while it varies from 0.3 to 0.7 for asymmetric shoe length. Moreover, relative investigation of automobile drum brake and disc brake was presented by using a systematic extensive approach based on simulation. The findings showed that the friction radius has a major effect on brake pressure and hence the friction coefficient [14]. It has been also discovered that disc brakes have a more stable frictional behaviour as compared to drum brakes.

The electric vehicle system model is evaluated with simulink environment for achieving closed loop of energy in case of regenerative braking system. The simulations revealed that the combined auxiliary brake has consistent efficiency in all operating conditions, meets auxiliary brake torque demands, and significantly extends the retarding time of a conventional eddy current retarder [15]. The stability of vehicle is primarily depends on center of gravity (CG) of vehicle, however in electric cars, center of gravity (CG) of vehicle may vary as per the architectural arrangements of drive train and sub-systems. Thereby the detailed analysis is conducted to examine different retrofitted EV architectures which can be evaluated using different mass distributions while keeping vehicle mass and dimensions in mind by using Simulink [16]. Furthermore, some researchers designed the MATLAB/Simulink program to provide the best power flow response for the electric vehicle energy system through a development of small car. A systematic approach is suggested for getting the desired range of driving of electric vehicles [17]. In most of the literatures, simulation through 
Simulink/MATLAB is carried out to examine the effectiveness of system with various parameters and their significant results. Since the simulation is considered as a powerful tool for primary evaluation of proposed system, authors have tried to employ the simulink tool to assess the actual feasibility of proposed smart system.

Road safety is prominently depends on good braking system and control mechanism. Despite the fact that new cars use sophisticated safety techniques/accessories, traditional vehicles on the road lack safety systems. In view of this, authors planned to introduce an auxiliary module which can be used for traditional vehicle which are already present on the road.

In this paper, we have suggested the smart braking model for controlling the car with automation through simulation if there are any obstacles detected from the front of the vehicle. Around the same time, as the vehicle speed exceeds $80 \mathrm{~km} / \mathrm{hr}$, emergency contactless brakes are introduced to stabilize the vehicle speed abruptly if the brakes are applied. The previous work related to braking systems and electric vehicles are shown in Table 1.

Table 1. Summary of previous work related to braking system and electric vehicles

\begin{tabular}{|c|c|c|c|}
\hline Authors and Year & Description & Method Adopted & Remark \\
\hline $\begin{array}{l}\text { Shital M. Kalikate, } \\
\text { Satyajit R. Patil, and } \\
\text { Suresh M. Sawant } \\
\text { (2018) [11] }\end{array}$ & $\begin{array}{l}\text { Performance } \\
\text { estimation of MR } \\
\text { brakes }\end{array}$ & $\begin{array}{l}\text { Simulation of } \\
\text { proposed braking } \\
\text { model by using } \\
\text { Simulink platform }\end{array}$ & $\begin{array}{l}\text { Feasibility of MR brake system is } \\
\text { assessed with findings that six discs are } \\
\text { required to satisfy the braking } \\
\text { requirement which may not be feasible. }\end{array}$ \\
\hline $\begin{array}{l}\text { Alemani, Jens } \\
\text { Wahlström, and UIf } \\
\text { Olofsson (2018) [9] }\end{array}$ & $\begin{array}{l}\text { Evaluation of } \\
\text { Particulate matter } \\
\text { Emissions from } \\
\text { brakes }\end{array}$ & $\begin{array}{l}\text { Pin on disc } \\
\text { Apparatus }\end{array}$ & $\begin{array}{l}\text { The wear particles coming out from } \\
\text { brakes are studied and according to this } \\
\text { study, Frictional power is the most } \\
\text { important braking system parameter. }\end{array}$ \\
\hline $\begin{array}{l}\text { H. P. Khairnar, V. M. } \\
\text { Phalle, and S. S. } \\
\text { Mantha (2016) [14] }\end{array}$ & $\begin{array}{l}\text { Comparative study of } \\
\text { disc brake and drum } \\
\text { brake considering } \\
\text { frictional analysis }\end{array}$ & $\begin{array}{l}\text { Virtual } \\
\text { Matlab/Simulink } \\
\text { models for drum } \\
\text { and disc brakes }\end{array}$ & $\begin{array}{l}\text { An assessment technique is presented } \\
\text { for the coefficient of friction of the } \\
\text { drum-shoe and rotor disk-pad interface. }\end{array}$ \\
\hline $\begin{array}{l}\text { V. Sanjay Kumar, S. } \\
\text { Nair Ashish, I.V. } \\
\text { Gowtham, S.P. Ashwin } \\
\text { Balaji, E. Prabhu (2020) } \\
\text { [2] }\end{array}$ & $\begin{array}{l}\text { Smart driver assistive } \\
\text { techniques }\end{array}$ & $\begin{array}{l}\text { Matlab based } \\
\text { formulation of } \\
\text { model with } \\
\text { Risberry pi, sensors }\end{array}$ & $\begin{array}{l}\text { The smart control system based on } \\
\text { drowsiness detection, alcohol detection, } \\
\text { and vehicular crash detection has been } \\
\text { implemented to enhance road safety. }\end{array}$ \\
\hline $\begin{array}{l}\text { H. P. Khairnar, V. M. } \\
\text { Phalle, and S. S. } \\
\text { Mantha (2015) [13] }\end{array}$ & $\begin{array}{l}\text { Determination of } \\
\text { coefficient of friction } \\
\text { under different } \\
\text { conditions of } \\
\text { longitudinal forces } \\
\text { for drum shoe } \\
\text { interface }\end{array}$ & $\begin{array}{l}\text { Simulink model for } \\
\text { single wheel drum } \\
\text { brake }\end{array}$ & $\begin{array}{l}\text { A systematic approach is presented for } \\
\text { effective evaluation of drum brake } \\
\text { system considering longitudinal forces. } \\
\text { The maximum value for coefficient of } \\
\text { friction is reported as } 0.7 \text { for } \\
\text { symmetrical shoe length which may vary } \\
\text { for asymmetrical shoe from } 0.3-0.7\end{array}$ \\
\hline $\begin{array}{c}\text { Zhaohua Wang, } \\
\text { Gangfeng Tan, } \\
\text { Xiaomeng Shen, Yifan } \\
\text { Ye, Quan Zhou, } \\
\text { Xiaolong He (2015) } \\
{[15]}\end{array}$ & $\begin{array}{l}\text { Performance } \\
\text { evaluation of hybrid } \\
\text { electric vehicles with } \\
\text { contactless auxiliary } \\
\text { braking system }\end{array}$ & $\begin{array}{l}\text { Simulink block } \\
\text { models are } \\
\text { prepared for } \\
\text { complete vehicle } \\
\text { model }\end{array}$ & $\begin{array}{l}\text { The combination of eddy current } \\
\text { retarder with regenerative brakes is } \\
\text { proposed to improve energy efficiency } \\
\text { of system. }\end{array}$ \\
\hline $\begin{array}{l}\text { María del Carmen } \\
\text { Pardo-Ferreira, Juan } \\
\text { Carlos Rubio-Romero, } \\
\text { Fuensanta Carmen } \\
\text { Galindo-Reyes, } \\
\text { Antonio Lopez- } \\
\text { Arquillos (2020) [8] } \\
\end{array}$ & $\begin{array}{l}\text { The quiet nature of } \\
\text { electric vehicle based } \\
\text { on work related road } \\
\text { safety is analysed } \\
\text { based on drivers' } \\
\text { perception. }\end{array}$ & $\begin{array}{l}\text { Drivers' survey to } \\
\text { analyze their } \\
\text { perception related } \\
\text { to low noise of } \\
\text { electric vehicles }\end{array}$ & $\begin{array}{l}\text { Electric vehicles are difficult to hear for } \\
\text { pedestrians especially in urban traffic } \\
\text { region. }\end{array}$ \\
\hline $\begin{array}{l}\text { Bambang Sri Kaloko, } \\
\text { Soebagio, Mauridhi } \\
\text { Hery Purnomo (2011) }\end{array}$ & $\begin{array}{l}\text { Design of electric } \\
\text { vehicles model }\end{array}$ & $\begin{array}{l}\text { MATLAB/Simulink } \\
\text { based simulation }\end{array}$ & $\begin{array}{l}\text { Battery capacity requirement is } \\
\text { estimated based on proposed model in } \\
\text { Simulink. }\end{array}$ \\
\hline
\end{tabular}




\section{SIMULINK MODELING}

Simulating the action of a real-world mechanism or device across sequence is known simulation. Bratley et al. defines modelling or simulation as a method of conducting a device model with the appropriate inputs and monitoring the appropriate outputs [18]. Models are required for simulations; the model shows the major features or behaviours of the chosen structure or mechanism, while the simulation represents the model's progression across period. Simulation often applies when a particular structure is not available or it may be unsafe or unethical to partake in, or where it is planned, but not yet established, or actually cannot exist. In view of this, authors proposed model of intelligent braking system. It has been modelled with simulink platform using MATLAB. Numerous situations, such as obstacle detection and brake blending are not feasible with a single control module, but they can be applied to a device using a state flow algorithm. The state flow algorithm consist of set of possible commands based on ifelse conditions of input parameters.

\subsection{Estimation algorithm for Smart Braking}

The simulation techniques are getting popular for investigation of operational as well as organizational systems. Fig. 1 shows the model verification architecture scheme in case of simulation. Furthermore, In order to perform the simulation, authors adopted the simulation full cycle procedure explained by previous researchers as shown in Fig. 2.

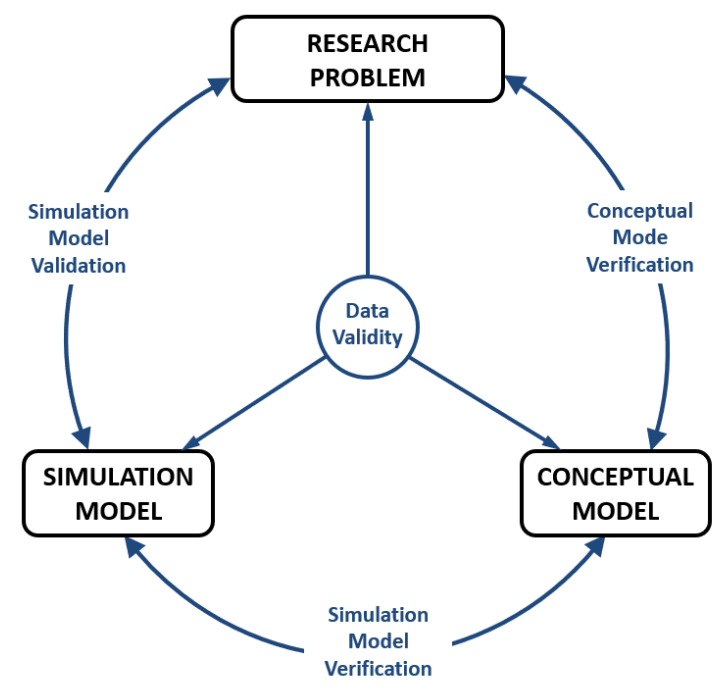

Fig. 1. Model architecture for verification [19]

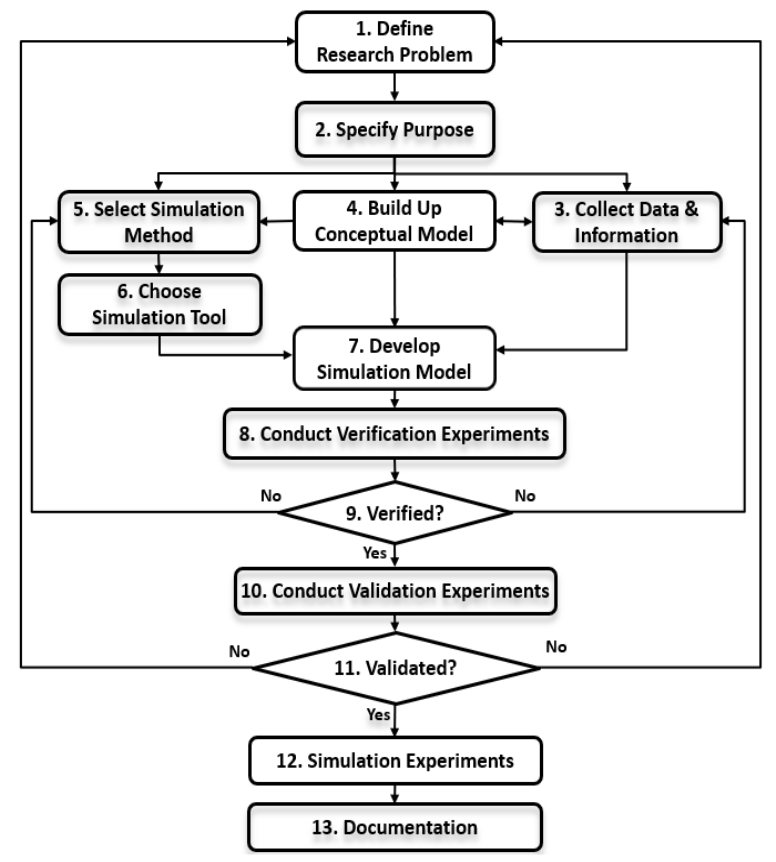

Fig. 2. Simulation modelling procedure [19]

The formal simulation process followed by a previous analysis of researchers allows a definite approach to problem solving. It consists of fundamental measures from problem description to experiments in simulation. This technique was accompanied by the proposed smart braking system model to obtain real-time vehicle braking control as explained in section 3.2.

\subsection{Control Strategy}

Various control methods such as fuzzy logicbased methodology, artificial neural network, deep learning, and others are available for realtime control and monitoring of conceptual processes.

Since Driver distraction is caused by a number of factors, there might be possibilty of fatal. Our main objective in this regards was to create a model that can deal with certain obstacle scenarios. At the same time, brake blending was introduced to allow for quicker vehicle control. In accordance with these requirements, the simulink block has been chosen as shown in Fig. 3. The algorithm for systematic state flow is produced on the basis of control conditions previously described. The if-else conditions provide an important monitor for the proper execution of the flow map. Using the chosen approach and technique, a computer-based simulation model is built for the conceptual model of smart braking system. 


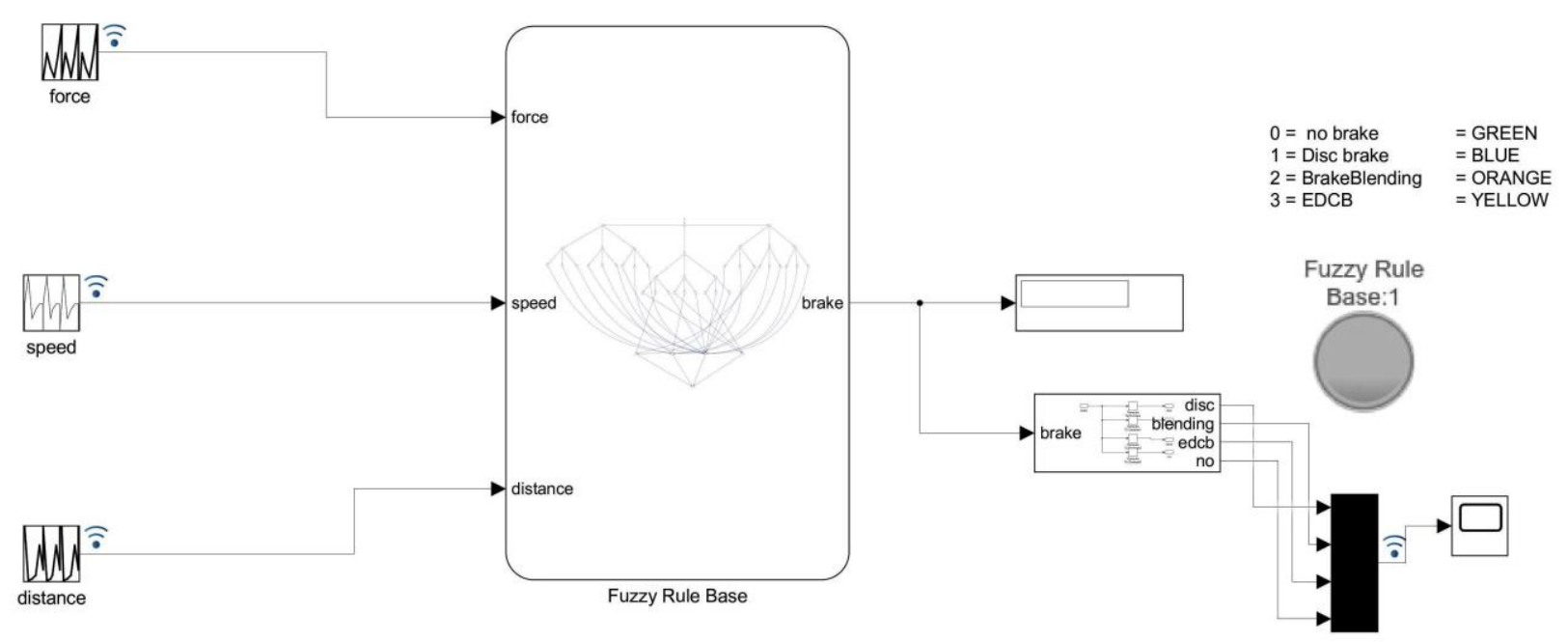

Fig. 3. Architecture of Intelligent Braking System

\subsection{Smart Braking System}

The drivers' force gained at actual brake pedal, real time speed of vehicle and distance of obstacle are selected as input parameters for the smart barking model as shown in Fig. 3. The braking force was split into two categories, namely the low braking force and the high braking force. The real time speed of vehicle has been considered as second input parameter with speed level of high, medium and low. Moreover, third parameter obstacle distance which was further categorized as no obstacle, obstacle at moderate distance and close obstacle.

The If-else conditions were incorporated successfully to achieve the desired output from the smart braking model system. The indicator shows the necessary actions chosen by system. Finally, the performance of system was evaluated with various real time conditions of automobile vehicle. Fig. 4 shows the subsystem used for brake selection based on decision of model.

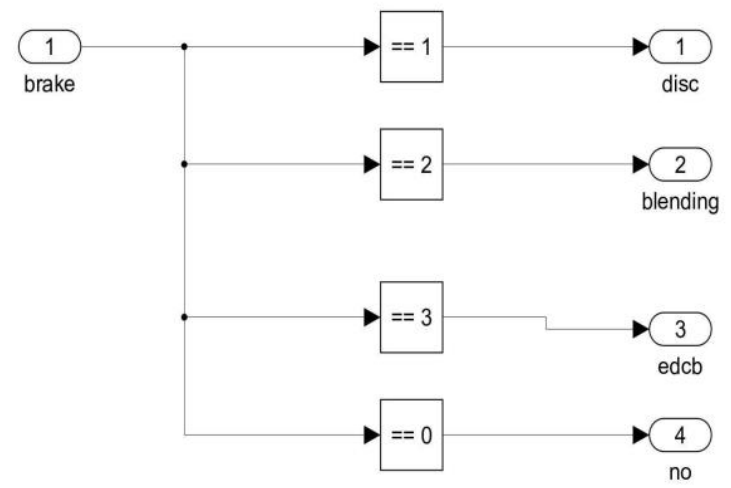

Fig. 4. Subsystem for selection of brakes

\section{RESULTS AND DISCUSSION}

Key modelling and simulation challenges include the acquisition of reliable knowledge sources on the appropriate set of key features and behaviour used in building the model, the use of simpler approaches and assumptions within the model as well as the reliability and validation of the simulation results. The result obtained from smart braking system has been shown in Fig. 5.

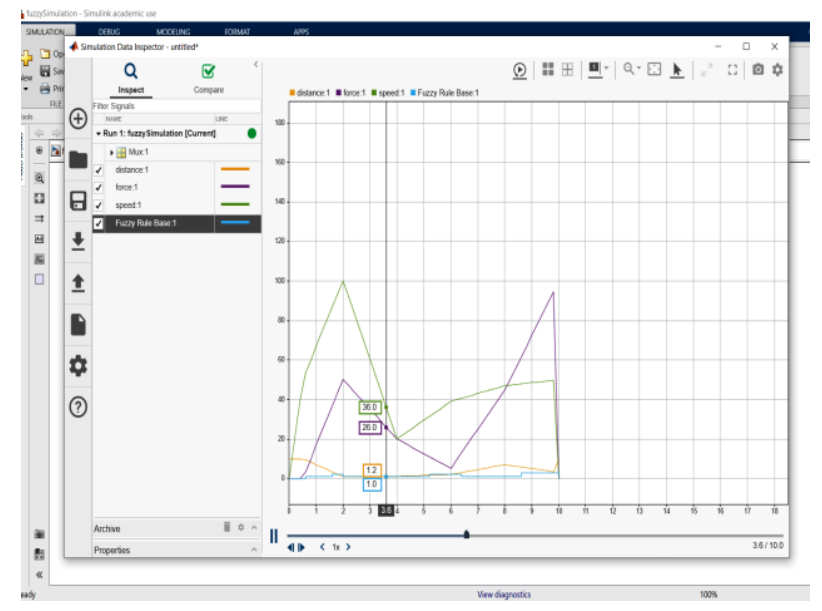

Fig. 5. Result of simulation for smart braking

The proper selection of brake such as disc brake or contactless brakes or combination of both was successfully achieved with the smart braking system. The result reveals that when the vehicle's speed exceeds $80 \mathrm{~km} / \mathrm{h}$ and the driver wishes to apply a brake, the contactless brakes would be activated to regulate the vehicle's speed at the time for quick control of speed. 
Eventually, as obstacle is detected nearby to the vehicle, the automatic control system with prior indication to road users has been adopted with simulation environment. The Fig. 6 shows the capability of smart braking system with various possible conditions and subsequent control strategy at every situations sensed by the model. With the simultaneous implementation of brake pedal force and vehicle tracking methodology, the innovative monitoring method for vehicle speed control is studied. Our findings indicate that the combination would work well with a smart model approach as shown in Fig. 7. The blue line displays the control system.

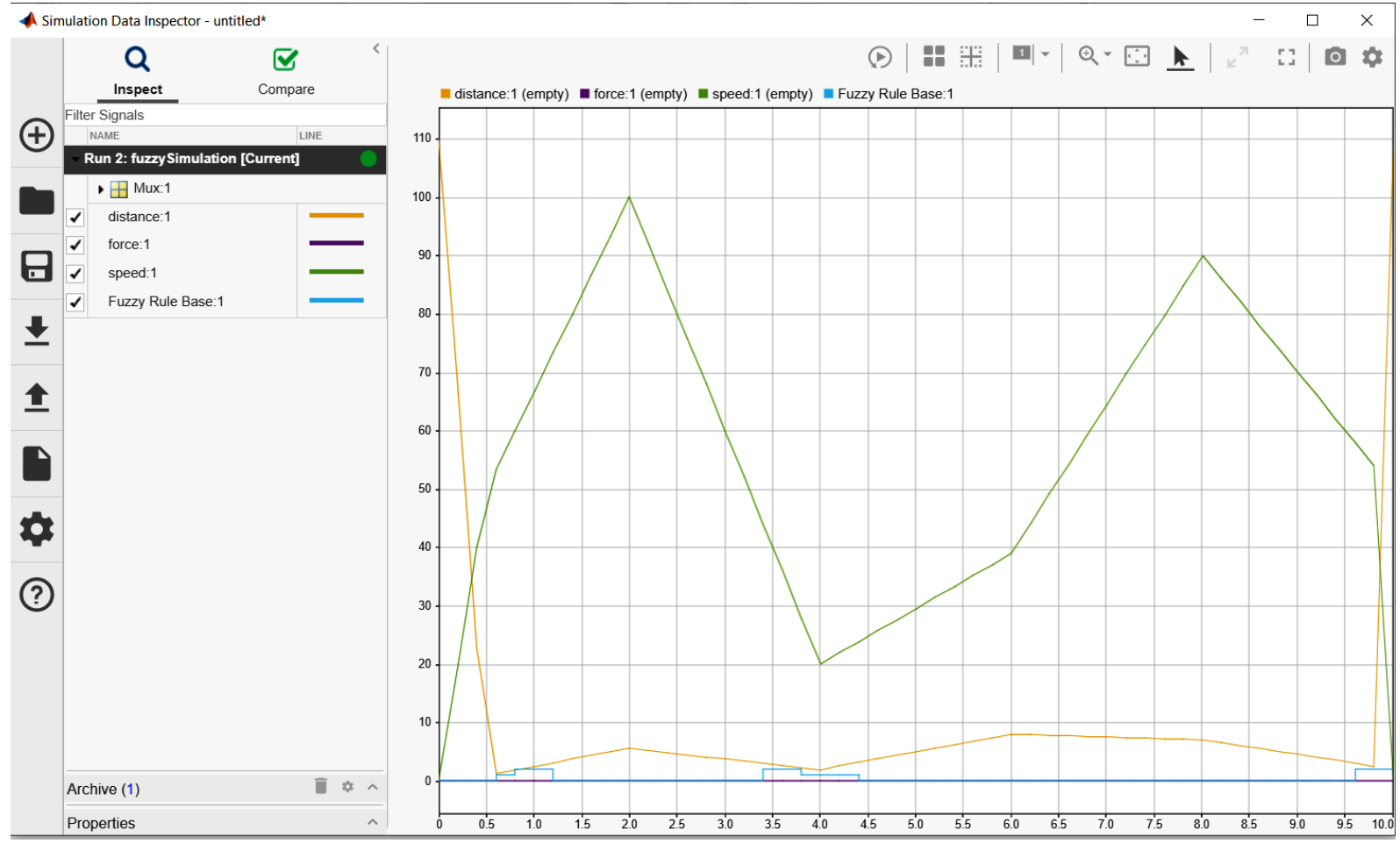

Fig. 6. Simulation Data Inspector results when obstacle detected and no brake pedal force applied

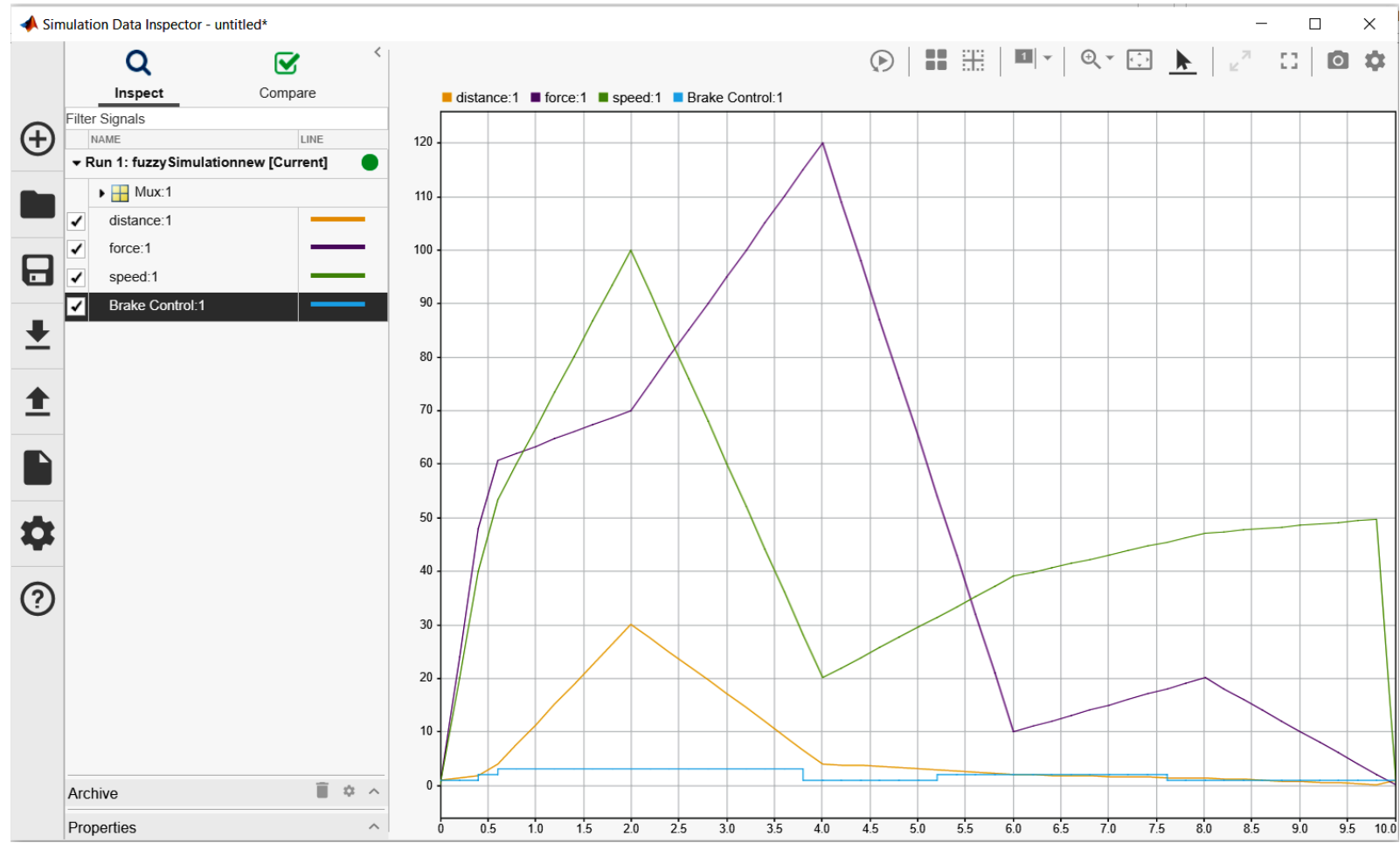

Fig. 7. Simulation Data Inspector results when obstacle detected and brake pedal force applied 
To observe the feasibility of the proposed model, the range of contextual situations is assessed. The outcomes achieved in all examind cases are consistent with the predicted results. As per the proposed conditions for braking situations, control strategies are successful for every possible conditions. What's more, the authors have assessed the operating conditions

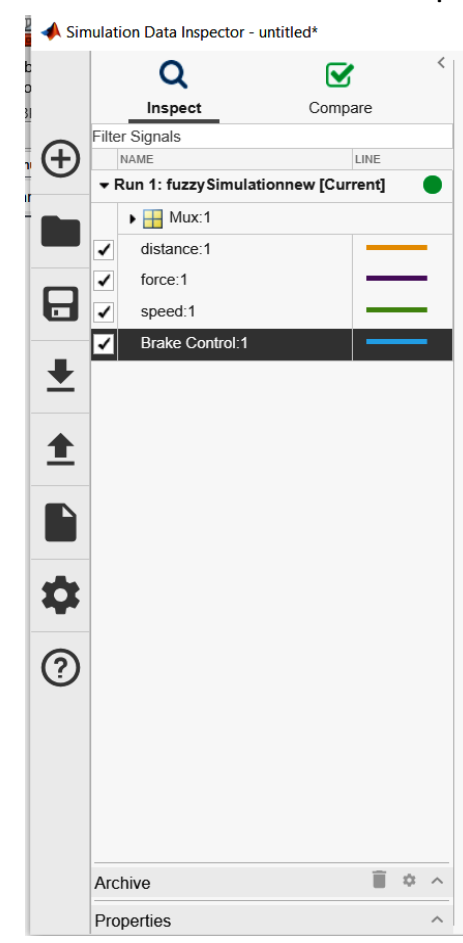

for the normal vehicle either without the driver brake or without any obstacles through simulink environement as shown in Fig. 8. In accordance with the circumstances, the brake force line and the output brake control scheme are overlapped. It indicates the output braking scheme/strength would be null if no obstacle detection and also brake pedal force is not found.

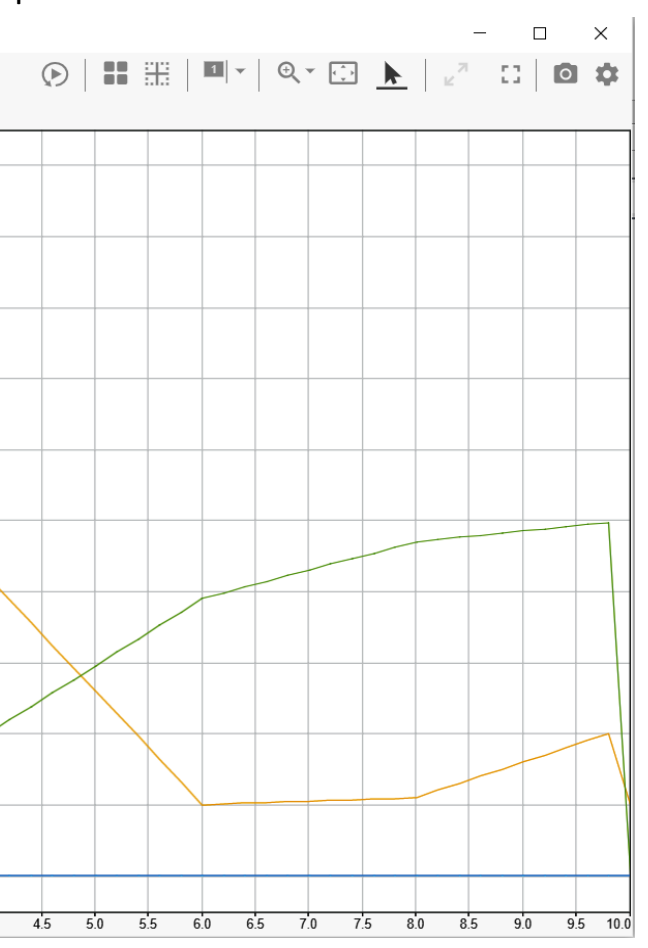

Fig. 8. Simulation Data Inspector results when obstacle not detected and brake pedal force not applied

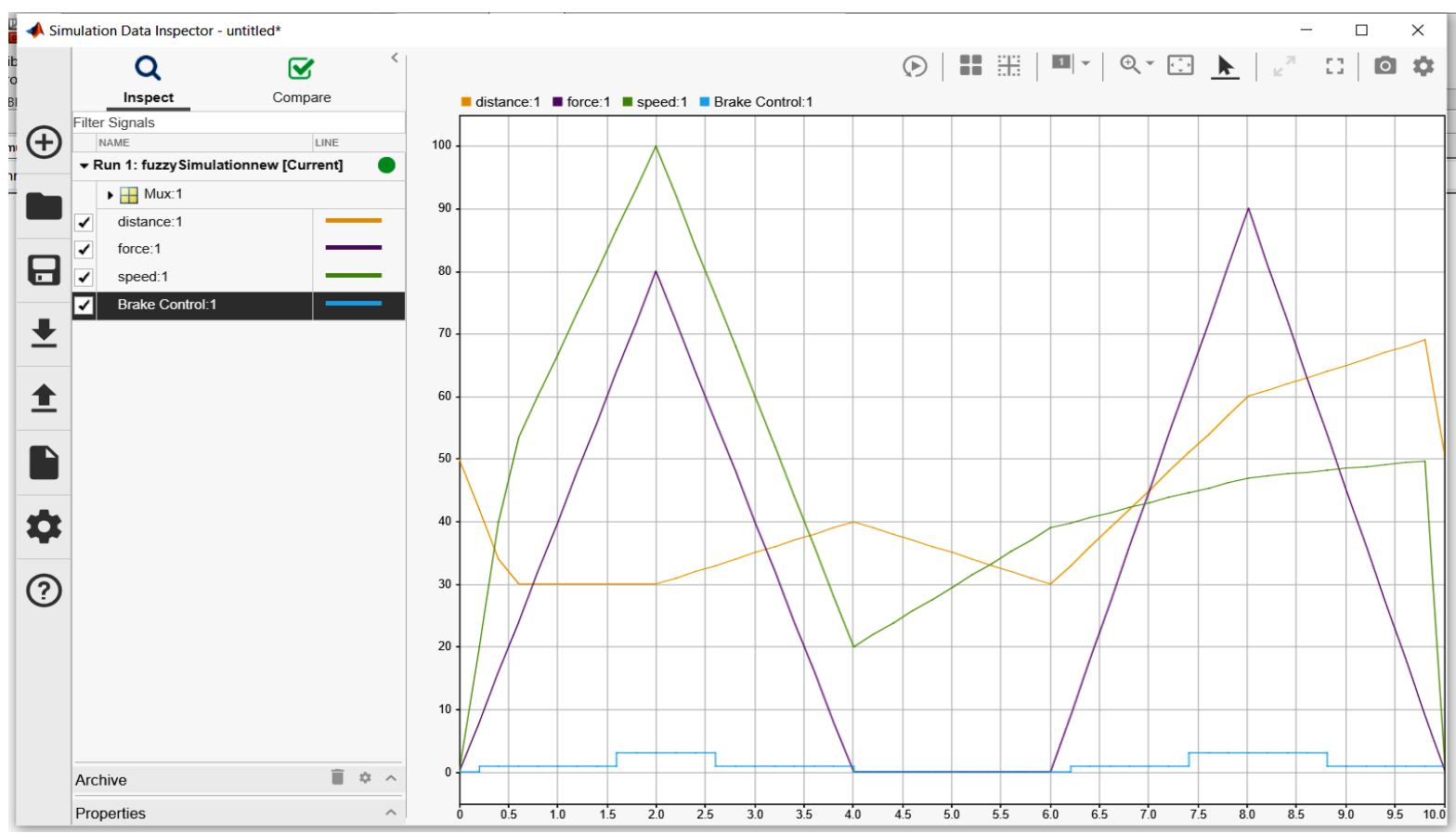

Fig. 9. Simulation Data Inspector results when obstacle not detected and brake pedal force applied

Fig. 9 shows the control strategy at the will of driver. If the obstacle is not detected, however, driver wish to stop or slow down the vehicle then the proposed smart model exibit the smooth and quick control of vehicle as a result of blending of brakes. 
The previous research focussed on different simulink based model to calculate coefficient of friction [13], performance of MR brake [11], electric vehicle modelling [17], simulation for safety [20], design of ABS controller [21] related to electric vehicles and braking system. To this end, we are able to obtain consistent results with the smart braking control system. In our case, the stopping time obtained is nearly equal to the stopping time computed by previous researchers [11]. What's more, the execution of proposed flow sequnce for smart braking strategy is in line with the control strategy mentioned by automobile scientists [2]. The Robert Oshana [22] has presented a schematic approch for embedded software architecture which follows the same methods of application development as other modes of software development such as the Waterfall model as shown in Fig. 10. Considering the same, firstly, we adopted the braking control strategy by employing state flow algorithm through Simulink. The integration with the embedded techniques helps to bring out idea of any complex control system in to real time application [22]. Thereby, it is foremost criteria for such practices is to design the suitable controller as per requirement. In quest of this, we followed state flow algorithm to develop control strategy. The feasibility is evaluated with simulation environemt with various trials as discussed in result section.

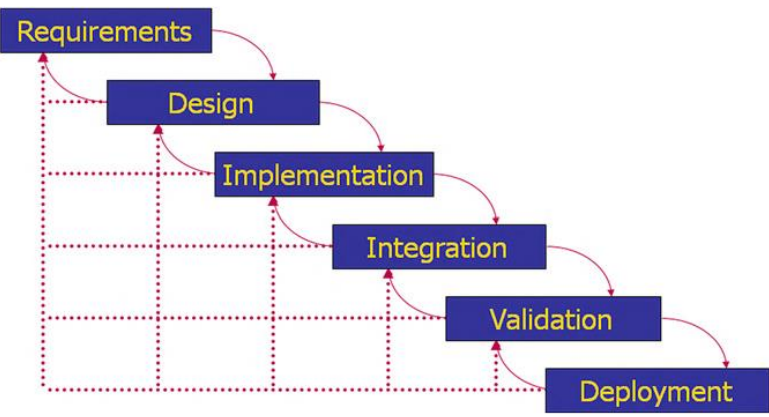

Fig. 10. Stages in Waterfall development model [22]

The numerous research articles are intended on drivers' safety and driver's assistive systems $[2,3,23]$. Considering the prominent factors associated with safety and comfort, we designed our smart braking system and evaluated with performance patterns as per prescribed conditions. Thus, our proposed braking scheme would be helpful for road users and drivers to boost the global safety. The future work of the our proposed system will be implementation of smart control strategy with real time hardware in loop environement on test bed.

\section{CONCLUSION}

This study presents comprehensive model of smart braking system to enhance the safety for road users. The parameters chosen for this study was real time speed of vehicle, distance of obstacle from vehicle and force exerted on brake pedal by driver. The nature of brake blending is investigated using a simulation-based technique. The results obtained from simulink platform shows the correctness in operation performed by model as a result of state flow technique. The outcome of the simulation results is appended briefly as follows:

- The proper selection of brake type such as disc brake or contactless brakes or combination of both as per requirement was successfully achieved with the smart braking system;

- The vehicle control based on brake blending ensures the rapid control of speed of vehicle;

- Smart braking models have the ability to efficiently use such an auxiliary contactless braking system;

- The simulation results show the feasibility of model for real time application with aid of certain hardware in loop system;

- Finally, overall road safety, along with drivers and passengers, improves with smart braking system models.

\section{ACKNOWLEDGMENTS}

We are thankful to Technical Education Quality Improvement Programme (TEQIP-III) in Veermata Jijabai Technological Institute (VJTI), Mumbai, India for awarding financial assistantship to corresponding author.

\section{REFERENCES}

[1] V. A. Kalhapure, and H. P. Khairnar, Analytical and experimental investigation on wear performance of disc brake pad. Tribology in Industry, 42 (3), 2020: 345362. https://doi.org/10.24874/ti.852.02.20.05

[2] V.S. Kumar, S.N. Ashish, I.V. Gowtham, S.P. Ashwin Balaji, E. Prabhu, Smart driver 
assistance system using raspberry pi and sensor networks. Microprocessors and Microsystems, 79, 2020: 103275.

https://doi.org/10.1016/j.micpro.2020.1032 $\underline{75}$

[3] J. Nasar, P. Hecht, R. Wener, Mobile telephones, distracted attention, and pedestrian safety. Accident Analysis \& Prevention, 40 (1), 2008: 69-75. https://doi.org/10.1016/j.aap.2006.07.001

[4] M. Patel, S.K.L. Lal, D. Kavanagh, P. Rossiter, Applying neural network analysis on heart rate variability data to assess driver fatigue. Expert Systems with Applications, 38 (6), 2011: 7235-7242.

https://doi.org/10.1016/j.eswa.2010.12.028

[5] N.K. Naqvi, M.A. Quddus, M.P. Enoch, Do higher fuel prices help reduce road traffic accidents?. Accident Analysis \& Prevention, 135, 2020: 105353.

https://doi.org/10.1016/i.aap.2019.105353

[6] V. Gulati, National electric mobility mission plan 2020. Department of Heavy Industry, Ministry of Heavy Industries \& Public Enterprises, Government of India, 2012. https://dhi.nic.in/writereaddata/Content/NE MMP2020.pdf

[7] L. Maffei M. Masullo, Electric Vehicles and Urban Noise Control Policies. Archives of Acoustics, 39 (3), 2015: 333-341.

https://doi: 10.2478/aoa-2014-0038

[8] M. del C. Pardo-Ferreira, J.C. Rubio-Romero, F.C. Galindo-Reyes, A. Lopez-Arquillos, Work-related road safety: The impact of the low noise levels produced by electric vehicles according to experienced drivers. Safety Science, 121, 2020: 580-588. https://doi.org/10.1016/j.ssci.2019.02.021

[9] M. Alemani, J. Wahlström, U. Olofsson, On the influence of car brake system parameters on particulate matter emissions. Wear, 396-397, 2018: 67-74.

https://doi.org/10.1016/i.wear.2017.11.011

[10] D. Chinnappa Nanjunda, Impact of socioeconomic profiles on public health crisis of road traffic accidents: A qualitative study from South India. Clinical Epidemiology and Global Health, 9, 2021: 7-11.

https://doi.org/10.1016/i.cegh.2020.06.002

[11] S.M. Kalikate, S.R. Patil, S.M. Sawant, Simulation-based estimation of an automotive magnetorheological brake system performance. Journal of Advanced Research, 14, 2018: 43-51.

https://doi.org/10.1016/i.jare.2018.05.011

[12] J. Wu, H. Hu, Q. Li, S. Wang, J. Liang, Simulation and experimental investigation of a multi-pole multi-layer magnetorheological brake with superimposed magnetic fields. Mechatronics, p. 11, 2020: 102314 https://doi.org/10.1016/i.mechatronics.201 9.102314

[13] H.P. Khairnar, V.M. Phalle, S.S. Mantha, Estimation of automotive brake drum-shoe interface friction coefficient under varying conditions of longitudinal forces using Simulink. Friction, 3 (3), 2015: 214-227. https://doi.org/10.1007/s40544-015-0082-6

[14] H.P. Khairnar, V.M. Phalle, S.S. Mantha, Comparative Frictional Analysis of Automobile Drum and Disc Brakes. Tribology in Industry, 38 (1), 2016: 11-23.

[15] Z. Wang, G. Tan, X. Shen, Y. Ye, Q. Zhou, X. $\mathrm{He}$, Performance analysis of a contactless combined auxiliary brake for hybrid electric vehicle. IEEE International Transportation Electrification Conference (ITEC), Chennai, India, Aug. 2015, pp.1-6.

[16] H. Mazumder, M.M.A. E. Hassan, M. Ektesabi, and A. Kapoor, Performance analysis of EV for different mass distributions to ensure safe handling. Energy Procedia, 14, 2012: 949-954.

https://doi.org/10.1016/j.egypro.2011.12.103 8

[17] B.S. Kaloko, Soebagio, M.H. Purnomo, Design and Development of Small Electric Vehicle using MATLAB/Simulink. International Journal of Computer Applications, 24, (6), 2011: 19-23. https://doi: 10.5120/2960-3940

[18] P. Bratley, B. L. Fox, and L. E. Schrage, $A$ Guide to Simulation. New York. Springer New York, 1987.

[19] C. Yin A. McKay, Introduction to Modeling and Simulation Techniques. The 8th International Symposium on Computational Intelligence and Industrial Applications and The $12^{\text {th }}$ China-Japan International Workshop on Information Technology and Control Applications, 02-06 November 2018, Tengzhou, China.

[20] W. Young, A. Sobhani, M.G. Lenné, M. Sarvi, Simulation of safety: A review of the state of the art in road safety simulation modelling. 
Accident Analysis \& Prevention, 66, 2014: 89103.

https://doi.org/10.1016/i.aap.2014.01.008|

[21] Wenjuan Li, Xudong Wang, Xue Leng, Meng Wang, Modeling and simulation of automobile braking system based on kinetic energy conversion. IEEE Vehicle Power and Propulsion Conference, Harbin, Hei Longjiang, China, September 2008, pp.1-3. https://doi.org/10.1109/VPPC.2008.4677741

[22] R. Oshana, Software Engineering of Embedded and Real-Time Systems. Software Engineering for Embedded Systems, Methods,
Practical Techniques, and Applications. Elsevier, 2013, pp.1-32. https://doi.org/10.1016/B978-0-12-4159174.00001-3

[23] J. P. Vasconez, M. Viscaino, L. Guevara, F.A. Cheein, A fuzzy-based driver assistance system using human cognitive parameters and driving style information. Cognitive Systems Research, 64, 2020: 174-190. https://doi.org/10.1016/i.cogsys.2020.08.00 $\underline{7}$ 